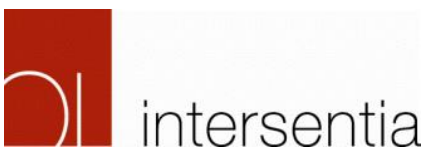

This chapter was originally published in:

\title{
Weaving Intellectual Property Policy in Small Island Developing States
}

\author{
Miranda Forsyth and Sue Farran \\ Published in September 2015 by Intersentia \\ www.intersentia.co.uk
}

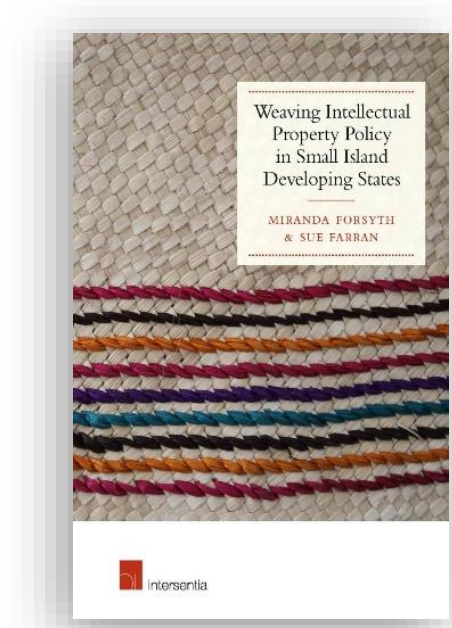

\section{For more information on the book or to purchase}

https:/intersentia.com/en/weaving-intellectual-property-policy-insmall-island-developing-states.html

This chapter is made available under the terms of the Creative Commons Attribution, NonCommercial, ShareAlike Creative Commons Licence (https://creativecommons.org/licenses/by-ncsa/4.0/), which permits non-commercial re-use, distribution, and reproduction in any medium, provided the original work is properly cited and derived works are published under the same licence.

For any queries, or for commercial re-use, please contact Intersentia at mail@intersentia.co.uk or on +44 (0) 1223370170.

\section{Featured Recommendations}

Introduction to South Pacific

Law, Fourth Edition

Jennifer Corrin and Don Paterson

ISBN 978-1-78068-412-3

$\mathrm{c}+440 \mathrm{pp}$.
Courts and Civil Procedure in the South Pacific, Second Edition

Jennifer Corrin and David

Bamford

ISBN 978-1-78068-280-8

1 xxxii +398 pp. 


\title{
WEAVING INTELLECTUAL PROPERTY POLICY IN SMALL ISLAND DEVELOPING STATES
}

\author{
Miranda Forsyth \\ Sue FARRAN
}

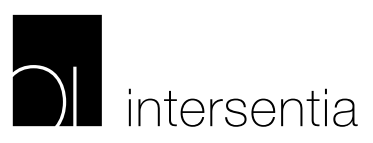

Cambridge - Antwerp - Portland 


\section{CONTENTS}

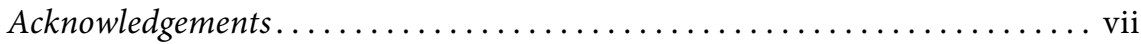

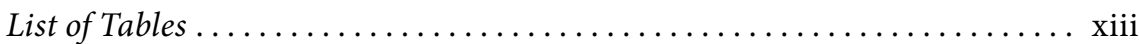

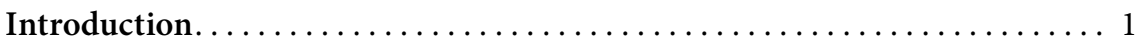

1. What is Intellectual Property and Why is it Relevant for Development?... 2

2. Pacific Island States and Development. .................. 7

3. Pacific Island States and the Global Intellectual Property Framework . . . 14

4. Overview of the Book ............................ 17

\section{Chapter 1.}

Intellectual Property and Development: The Issues Viewed through

a Pacific Islands Prism . . . . . . . . . . . . . . . . . . . . . . . . . . . . 23

1. The Current Dominant Approach to Development.............. 25

2. Pacific Island Countries as Examples of the Dominant Approach to Intellectual Property and Development ............... 27

2.1. Intellectual Property Developments in Pacific Island Countries

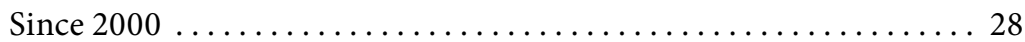

2.2. The Free Trade Agreement Mechanism: Pacific Island Examples . . . 32

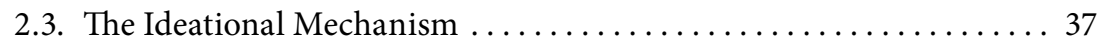

2.3.1. Intellectual Property as a Stimulant for Innovation and

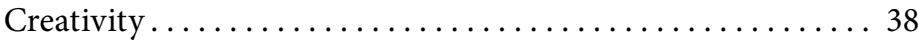

2.3.2. Intellectual Property as a Means of Fostering Technology Transfer between Developed and Developing Countries ..... 43

2.3.3. Intellectual Property as Promoting Economic Growth .... . . 46

2.3.4. Intellectual Property as Protecting Traditional Knowledge and Traditional Expressions of Culture . . . . . . . . 50

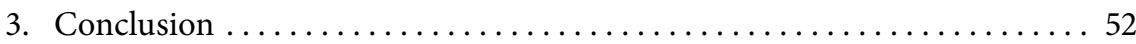

\section{Chapter 2.}

Health and Issues of Access to Medicine ................... 53

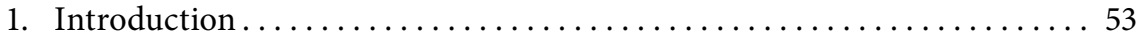

2. Health, Medicine and Intellectual Property $\ldots \ldots \ldots \ldots \ldots \ldots \ldots \ldots 4$

3. The Impact of the Global North on Pacific Health . . . . . . . . . . . . 57

4. The Role of Patents . . . . . . . . . . . . . . . . . . . . . . . . . . . 58 
5. Contrasting Case Studies from India and Vanuatu ............ 64

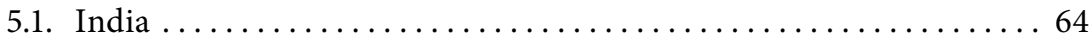

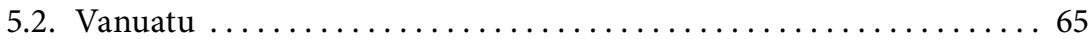

6. The Potentially Adverse Effects of WTO Accession. . . . . . . . . . 68

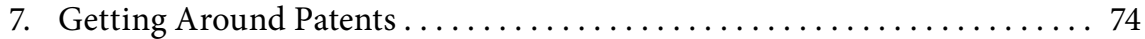

7.1. Exceptions to Patentability .................... 75

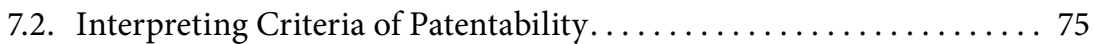

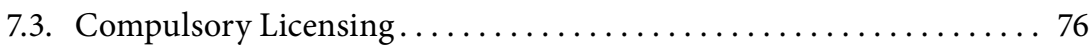

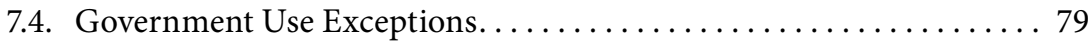

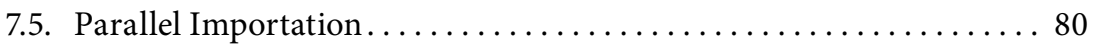

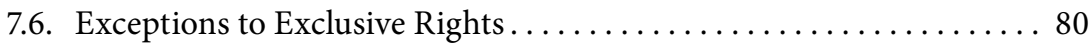

7.7. TRIPS Plus Measures . . . . . . . . . . . . . . . . . . . . . 81

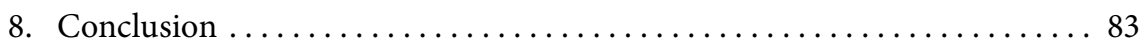

Chapter 3.

Access to Educational Resources . . . . . . . . . . . . . . . 85

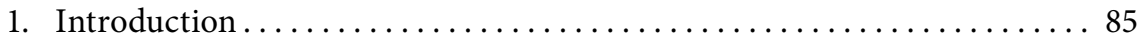

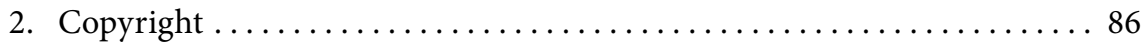

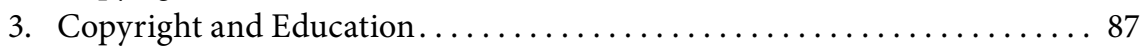

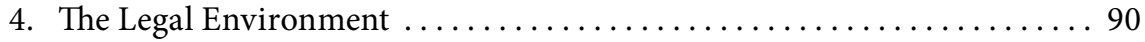

5. Understandings and Misunderstandings about Copyright in Practice ... 96

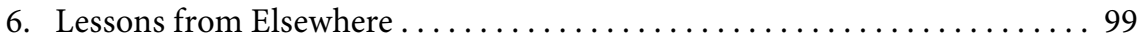

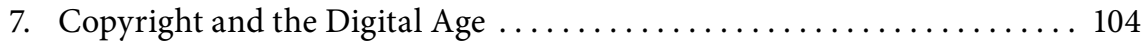

8. Pacific Initiatives in Educational Materials. . . . . . . . . . . . 106

9. Informal Education . . . . . . . . . . . . . . . . . . . . . . . 109

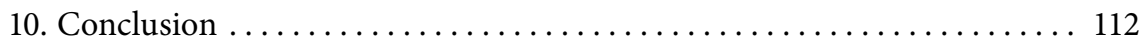

Chapter 4.

Problems with Importing the Global Intellectual Property Regime into Pacific Island Countries: Learning from Land . . . . . . . . . . . 115

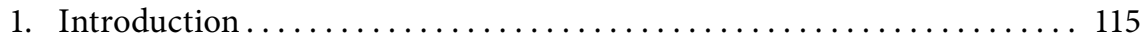

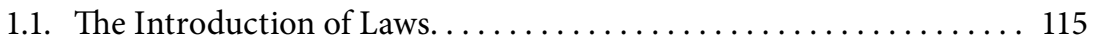

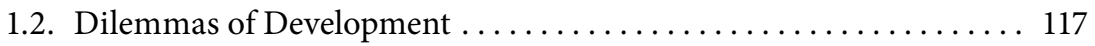

1.3. The Relevance of Land .......................... 118

2. Customary Land Tenure and Social Organisation. . . . . . . . . . 118

3. Understandings and Misunderstandings in Language and Concepts . . . 122

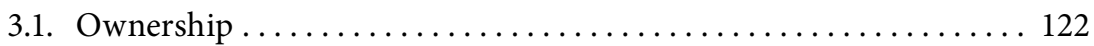

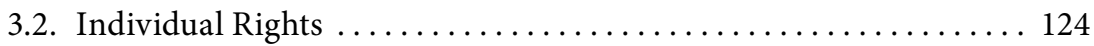

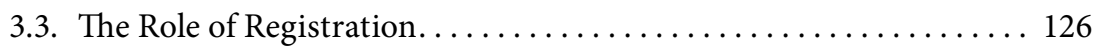

3.4. Land and the Social Framework. .................. 127

3.5. The Consequences of Commoditising Land and its Resources. . . . 130 
4. The Application of Transplanted Legal Institutions and Forms . . . . . 131

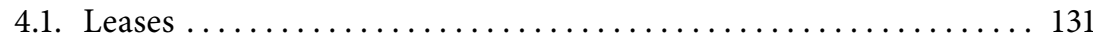

4.2. Reclaiming Customary Land Rights . . . . . . . . . . . 133

4.3. Applying Lessons from Land to Traditional Knowledge . . . . . . 135

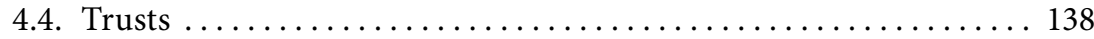

5. The Challenge of Addressing and Redressing Land Issues. . . . . . . . . 139

Chapter 5.

Setting Out a New Approach to Intellectual Property and Development. . 143

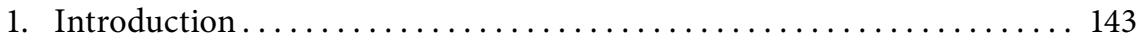

2. Current Critiques of the Intellectual Property and Development

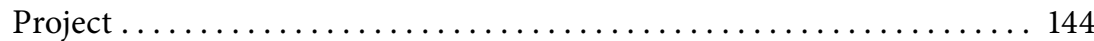

2.1. Changes at the International Level $\ldots \ldots \ldots \ldots \ldots \ldots \ldots \ldots \ldots$

2.2. Exhort Countries in the Global South to Implement the Flexibilities Available to them in TRIPS and Other Free Trade Agreements .................................. 148

2.3. Calibrate Intellectual Property Rights with National

Development Strategies . . . . . . . . . . . . . . . . . . . . 150

3. Key Theoretical Insights from Critical Development Studies and their Possibilities for Intellectual Property . . . . . . . . . . . 153

3.1. The Power of Discourse to Limit the Possibilities of Change . . . . . 153

3.2. The Necessity of Exposing the Operationalisation of Universalism . . . . . . . . . . . . . . . . . . . . . . . . . . 159

3.3. The Cultural Power of Law and the Limits of Law . . . . . . . . 162

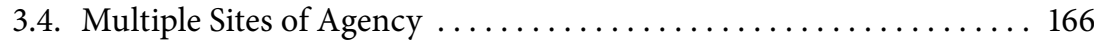

3.5. Concern with Relationality .................... 168

3.6. Promotion of Valuing and Embracing Pluralism . . . . . . . . . . . 169

3.7. Promotion of Interculturality $\ldots \ldots \ldots \ldots \ldots \ldots \ldots \ldots \ldots \ldots \ldots \ldots \ldots \ldots \ldots$

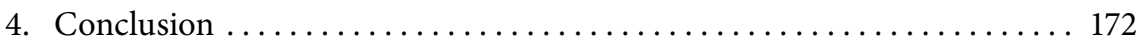

\section{Chapter 6.}

Intellectual Property and Technological Innovation in Pacific Island

Countries: The Example of Sustainable Sea Transport . . . . . . . . . . . . 175

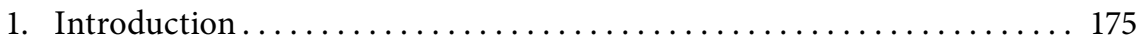

2. Sea Transport Issues in the Pacific Islands Region and the Current Development Paradigm . . . . . . . . . . . . . . . . . . . . . 177

3. An Emerging New Approach to Sea Transport ................ 180

4. The Sustainable Sea Transport Network . . . . . . . . . . . . . . . . 182

5. Cultural Heritage. . . . . . . . . . . . . . . . . . . . . . 187

5.1. Examples of Canoe-Based Initiatives in the Region . . . . . . . . 188 
5.2. Why is Cultural Heritage being Linked to New Technology

Initiatives in this Area? . . . . . . . . . . . . . . . . . . 195

5.3. IP Issues that have Arisen in Relation to Cultural Revival . . . . . . . 197

6. Lessons to be Learnt from the Sustainable Sailing Initiative . . . . . . . . . 199

Chapter 7.

Branding, Certifying and Authenticating in Pacific Island Countries . . . . 205

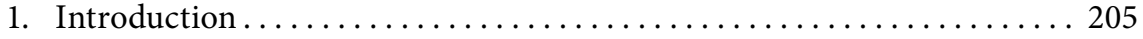

2. Trademarks....................................... 205

2.1. Trademark Potential in the Region . . . . . . . . . . . . . . 208

2.2. Trademarks and Cultural Heritage $\ldots \ldots \ldots \ldots \ldots \ldots \ldots \ldots \ldots . \ldots \ldots$

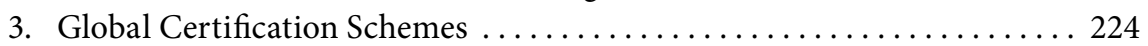

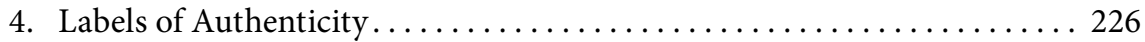

5. GIs and Collective Marks. . . . . . . . . . . . . . . . . . . . . . . . . . . 229

6. Customary Protocols, Education and Negative Publicity............ 231

7. Conclusion: Proposal for a Regional Cultural Heritage Branding Scheme. . . . . . . . . . . . . . . . . . . . . . . . . . . . . 233

Chapter 8.

The Regulation of Traditional Medicinal Knowledge in Pacific Island

Countries . . . . . . . . . . . . . . . . . . . . . . . . . . . . . . . . . . . . . . . . 237

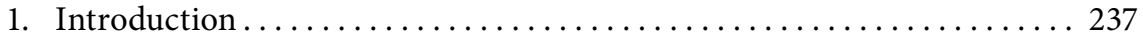

2. Intellectual Property Issues Raised by Traditional Medicinal

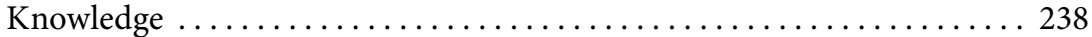

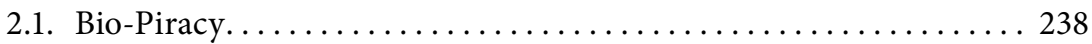

2.2. Traditional Medicinal Knowledge as the Basis of Local Business

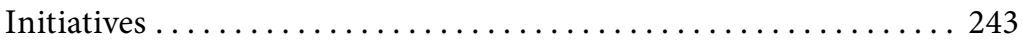

2.3. Preserving and Transmitting Traditional Medicinal Knowledge. . . 248

3. The Regulation of Traditional Medicinal Knowledge . . . . . . . . . . . . . . 249

3.1. Local Regulation of Maori Medicine in Cook Islands . . . . . . . . . 250

3.2. International Framework. . . . . . . . . . . . . . . . . . . . 253

3.3. Regional Frameworks. . . . . . . . . . . . . . . . . . . 255

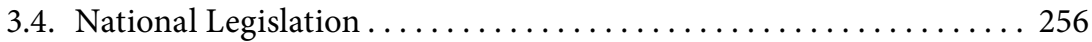

3.5. Creation of Databases to Record Traditional Knowledge . . . . . . 259

3.6. Research Permit Schemes and Bio-Cultural Protocols. . . . . . . . . . 261

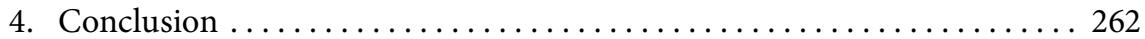

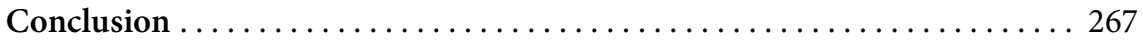

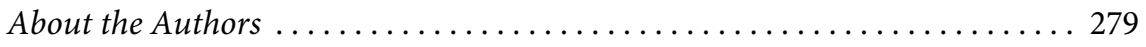




\section{ABOUT THE AUTHORS}

Dr Miranda Forsyth is a Fellow in the State Society and Governance in Melanesia Program in the College of Asia and the Pacific at the Australian National University.

Sue Farran is Professor of Laws at Northumbria University, Newcastle, an Adjunct Professor at the University of the South Pacific and an Associate Academic at the Centre for Pacific Studies, St Andrews University. 


\section{CHAPTER 7 \\ BRANDING, CERTIFYING AND AUTHENTICATING IN PACIFIC ISLAND COUNTRIES}

\section{INTRODUCTION}

The previous chapter discussed the way in which adopting a more pluralistic approach to intellectual property regulation in the context of technological innovation opens up new pathways and possibilities. In this chapter we explore another important aspect of intellectual property for developing countries, namely branding and culture- or place-based products and industries. As well as considering global forms of intellectual property such as trademarks and geographical indications of origin (GIs), we also explore locally modified mechanisms such as Fiji's experiments with a new batch of authenticity marks, a new regional organic standard and an ambitious move away from third-party certification to a participatory certification scheme. We discuss the complex issues the interplay between cultural heritage and intellectual property regulation raises for the region, both in terms of the desire to stop misappropriation of traditional knowledge by 'outsiders' and to facilitate its commercialisation by 'insiders', at the same time highlighting the problematic nature of such binaries. The various case studies and examples discussed in this chapter provide insights into the different strands of regulation that are available in this space and the benefits of engaging constructively with them. The chapter is structured around the exploration of how a range of different intellectual property mechanisms trademarks, global certification schemes, labels of authenticity, GIs, collective marks, customary protocols, education and negative publicity - are currently being used in the Pacific islands region, with a particular emphasis on Fiji as it has been the most active in this area to date.

\section{TRADEMARKS}

Trademarks are the most well-established of all the different types of global intellectual property rights in the region and all Pacific island countries have 
trademark legislation of one form or another. In essence, trademarks constitute words, symbols or devices which, in the form of an outward and recognisable representation placed on products, help consumers to identify their origins. Trademarks have the potential to fulfil a number of different policy objectives: allowing producers of goods and services to protect their investment in quality, building up of a reputation, aiding in advertising of products, and assisting consumers in assessing the quality and source of products. As businesses in the region become more complex, they are more likely to want to be able to stop competitors from 'free-riding' on these investments and indeed trademark disputes are those most commonly coming before the courts. ${ }^{1}$ Trademarks are reasonably straightforward to apply for and to administer compared with areas such as patent, and there are far more local applications for trademarks in the countries in the region than for other types of intellectual property rights (although the overwhelming majority in all countries are still by foreign companies). ${ }^{2}$ Trademarks also less problematic in terms of limiting access to crucial knowledge and technology than copyright and patent, and tend to be restricted to consumer goods and the tourism market.

The trademark legislation which exists in many countries in the region is extremely mixed in terms of scope and procedure. A major obstacle to the use of trademarks by local businesses in some countries is the cumbersome requirement to first register the mark in the UK (now the EU) before qualifying for domestic re-registration. This is still the case in some countries ${ }^{3}$ but it is now possible to register a trademark directly in Fiji, Tonga, Vanuatu, Samoa and Papua New Guinea. This dual registration process is expensive, requiring considerable legal assistance, and is also slow. ${ }^{4}$ Many of the trademark acts also have quite limited scope; for example in many countries it is not possible to register a trademark in relation to services.

Although the registration process for trademarks is simpler than for other forms of intellectual property right, it still requires some degree of infrastructure and administrative capacity. In Fiji, for example, registration was initially done through the Registrar of Trademarks, although in 2012 the Solicitor-General replaced the Registrar by virtue of the Trade-marks Amendment Decree. ${ }^{5}$ Under the Registrar the staff had no expertise in intellectual property and were regularly rotated to other areas, meaning that in practice marks were registered

See the PacLII.org Intellectual Property Virtual database <www.paclii.org/pacific-ip/> accessed 19/04/2015.

2 See the statistical country profiles on the WIPO database <www.wipo.int/ipstats/en/statistics/ country_profile/> accessed 19/04/2015.

3 Kiribati: Registration of United Kingdom Trademarks (Cap 88), Solomon Islands: Registration of United Kingdom Trademarks (Cap 180); Tuvalu: Registration of United Kingdom Trademarks Ordinance (Cap 63).

4 M. Forsyth, 'Tales of Intellectual Property in the South Pacific', State Society and Governance in Melanesia Discussion Paper 2012/13.

5 Trade-marks (Amendment) Decree 2012. 
without much scrutiny unless there was an opposition. However, if an opposition was lodged, the matter tended to pend indefinitely. It is not clear whether much has changed following the 2012 Decree: the Fiji Airways case study, below, seems to suggest that the situation remains the same. Very few national registries make effective use of information technology - electronic searches are only available in Papua New Guinea and Vanuatu, with the consequence that processing is slow, and record-keeping is poor, which has resulting consequences for the enforcement of rights. There are few intellectual property specialists in the region that can assist in effectively enforcing rights. Despite the existence of trademark laws in most countries in the region for many decades, there has also been very little litigation. In Fiji there have been around 20 reported cases, but only around 15 for the rest of the region. ${ }^{6}$ Border control systems for intellectual property are virtually non-existent in most of the region. ${ }^{7}$ In terms of enforcement, an important issue is also the question of cost. For international trademark owners, even those concerned by piracy of their trademarked goods, this must be assessed in relation to the relatively small size of the market. For local trademark owners, accessing the courts can be prohibitively expensive.

Some of these considerations have led to suggestions that one way to proceed may be by adopting a regional approach: ${ }^{8}$ the establishment of a regional trademark office in Papua New Guinea was first mooted in 2007.9 A Memorandum of Understanding about the establishment of such a facility has been drafted, and the Pacific Islands Forum Trade Ministers have been urging the member countries to sign it for a number of years. ${ }^{10}$ The slow progress of this initiative is probably related to concerns over national sovereignty and protection

$6 \quad$ See PacLII.org. A couple of the Fiji cases are appeal cases as well as first instance reports (as at $13 / 10 / 14)$.

7 Managing Intellectual Property, the Global IP Response, 'South Pacific: South Pacific Islands move to harmonise rules', 1 October 2007 <www.managingip.com/Article. aspx?ArticleID=1450528 $>$ accessed 19/04/2015.

8 Although WIPO now seems to be advocating a system for the worldwide filing of patents applications which almost inevitably would be dominated by the American perspective. See WIPO Sub-regional workshop on the Patent Cooperation Treaty in Asia-Pacific: PCT Procedures and Practices, 14 April 2013, WIPO/PCT/13/INF/3.

9 See Pacific Islands Forum Secretariat, Press Statement 99/07, 'Forum to Commission Study on Traditional Knowledge and Intellectual Property Rights', 13 August 2007 $<$ www.forumsec.org/pages.cfm/newsroom/press-statements/2013/2007/forum-<commissionstudy-on-traditional-knowledge-intellectual-property-rightsss.html> accessed 19/04/2015. P. Dranos, The Global Governance of Knowledge: Patents Offices and Their Clients, Cambridge University Press, Cambridge 2010, pp. 273-274, suggests that the Australian and New Zealand Patents Offices although not regional offices do in fact handle quite a lot of Pacific island work, while Bruce Berman suggests that a regional organisation would more likely be a multinational Asia-Pacific Patents Office: B. Berman, Making Innovation Pay: People who turn IP into Shareholder Value, John Wiley and Sons, London 2006, p. 136.

10 See Pacific Islands Forum Secretariat, Forum Trade Ministers Meeting, 19 July 2013, Apia, Outcomes Document <www.forumsec.org/resources/uploads/attachments/ documents/2013_FTMM_Outcomes.pdf > accessed 19/04/2015. 
of revenue streams from trademark applications. There are also a number of technical difficulties to overcome, in particular the lack of harmonisation in trademark legislation across the region. Although such a proposal seems to make practical sense, in fact there are many complex political, social and economic factors to take into account. ${ }^{11}$ One clear danger of such an initiative is that it will strip each individual country of the small amount of existing professional skills in intellectual property rights administration and may inhibit their future development. There are also questions about how a regional office would cope with the types of decisions about the intersection between traditional knowledge and trademarks discussed below.

\subsection{TRADEMARK POTENTIAL IN THE REGION}

Trademarks have considerable potential utility for a whole range of products. One example is in relation to emerging niche agricultural products. For instance, a new variety of papaya called 'Fiji Red' has recently been developed as part of a collaborative programme involving the Fijian Ministry of Agriculture, local farmers, Nature's Way Co-operative (a farmers' co-operative), the Secretariat of the Pacific Community and the Australian Centre for Research in Agriculture (ACIAR). One part of the programme built the capacity of local farmers to utilise new techniques such as local tree selection, flower bagging, and quality assessment to produce fresh fruit and seeds with qualities that can be assured. This is particularly critical in papaya where valued qualities such as redness, flavour and shape can easily be lost through cross-pollination with other neighbouring varieties. ${ }^{12}$ A trademark for such a product would be particularly helpful as it is impossible to tell from the outside whether a papaya is red and flavoursome on the inside. A secondary part of the programme has been the development of locally produced, high quality papaya seed. Nature's Way Co-operative, in close collaboration with the Fiji Ministry of Agriculture Research Division, has developed a certification scheme for the production and sale of 'Fiji Red' papaya seed. This locally produced seed replaces seed that was previously imported at a very high cost from the University of Hawai' $i$. This new seed scheme was launched in 2014, and to date the seed has been exported to

11 See M. Dornan and T. Newton Cain, 'Regional Service Delivery among Pacific Island Countries: An Assessment' (2014) 1(3) Asia and the Pacific Policy Studies 541 $<$ http://onlinelibrary.wiley.com/enhanced/doi/10.1002/app5.45> accessed 20/02/2015.

12 'Fiji Red' papaya was originally imported as Solo Sunrise from the University of Hawai'i, from this seed a selection process was done over two generations looking for the best performing trees under the conditions found in the Western Division of Viti Levu. The fruit that is now exported through Nature's Way Cooperative is branded as Fiji Red and is intended to help exporters differentiate their product from the other papaya in both Australia and NZ. There are potentially plant variety rights issues also involved in this example, which will need to be taken more into account in such future developments. 
Samoa and Solomon Islands. While the seed packages are labelled distinctively, a trademark has not as yet been registered. If the seed market develops, there is clear benefit in having such a mechanism that would complement the certification scheme to allow the producers of the 'Fiji Red' seed to capitalise on their investment in quality development, and also benefit consumers in terms of quality guarantee. ${ }^{13}$

Trademarks may also be used productively in the handicraft industry, especially where these are being undermined by foreign imports of similar products, and where it is not always clear in local markets whether the handicraft is authentically local. For example, the Tagiilima Handicraft Association is a group of about 60 couples in Samoa, funded by NZ AID, who make handicrafts and whose products are sold in the local markets and overseas through a website, ${ }^{14}$ and through promotion at overseas trade fairs. The Association faces a continuing problem of their market share being taken by an online entrepreneur from New Zealand who comes and buys their products from the local market and then re-sells them online without referencing the Association and undercutting their own online market. In 2008 they registered their trademark, 'Tagiilima Handicraft'. ${ }^{15}$ Although it has not allowed them to take direct action against the online entrepreneur, they have found the trademark has assisted their business. The Director of the Association stated:

'when we registered it in 2008 we had advertisements on TV, radio and in the newspaper to raise awareness of the mark. Since then we have had a lot of changes. Our financial reports show that we have been selling more goods locally. Also we have more markets overseas and greater opportunity to go overseas and sell our goods. Also we take our goods to sell on the cruise boats and people always ask about our association and want to take our business cards. ${ }^{16}$

This case is a good example of trademark laws being successfully used to assist a grassroots business, although it was the marketing associated with the trademark

13 K. Stice, 'Fiji: Nature's Way Cooperative launches certified "Fiji Red" Papaya Seed', International Tropical Fruits Network <www.itfnet.org/v1/2014/04/fiji-nature\%E2\% $80 \% 99$ s-way-cooperative-launches-certified-\%E2\%80\%98fiji-red $\%$ E2\%80\%99-papaya-seed/> accessed 19/04/2015.

14 See also in Vanuatu the Mama Market Ambassador Workshops sponsored by NZ Aid aimed at ensuring that mass produced foreign made articles are replaced by locally crafted work: Vanuatu Daily Digest, 30/07/2014.

15 There have been other marks in New Zealand intended to authenticate Maori art works such as the Toi Iho Maori Made Mark, the Toi Iho Mainly Maori Mark, and the Toi Iho Maori Co-production Mark for Maori and non-Maori collaborative work which in combination allow for the recognition of cross-cultural influences. Launched in 2002 by Creative New Zealand, in 2009 it was decided to stop promoting the mark on the grounds that the commercial value of the mark had not been established: L. Helfer and G. Austin, Human Rights and Intellectual Property: Mapping the Global Interface, Cambridge University Press, Cambridge 2011, pp. 496-498.

16 Interview, 14 April 2011. 
that brought benefits rather than its defensive use against other manufacturers. ${ }^{17}$ A factor that undoubtedly contributed to its successful use was the financial support and technical assistance supplied by NZ AID. This demonstrates that active support networks are necessary if intellectual property laws are going to be meaningfully used by local businesses in the region. An intellectual property awareness-raising session held with local handicraft producers in Vanuatu in July 2015 revealed that there was a great deal of appetite amongst the producers for a scheme that allowed them to register their new designs. However, there was general dismay at the costs involved in so doing and the participants were also apparently 'shocked' to learn that they would be responsible for monitoring the copying, believing that the government should be responsible. ${ }^{18}$

\subsection{TRADEMARKS AND CULTURAL HERITAGE}

From a public policy perspective, one significant issue for the region has been concerns that trademarks could be used to misappropriate traditional knowledge. These concerns can be illustrated by the following case study of Fiji Airways' attempt to trademark fifteen different masi (traditional paper cloth) motifs, all of which are based on 'the rich storehouse of designs within the iTaukei [indigenous Fijian] heritage arts.' 19

In 2011 and 2012, Air Pacific, Fiji's national airline, ${ }^{20}$ undertook a re-branding strategy that included a new name, 'Fiji Airways', and a distinctive new look designed to highlight the company's Fijian roots. ${ }^{21}$ In 2012 the new brand was revealed, centring on a 'Teteva motif', claimed to be 'a striking new Masi symbol that epitomizes Fiji and enhances the new name of Fiji's national

17 See also the Hua Parakore indigenous verification and validation system for mahinga kai (food and product production) that has been initiated by Te Waka Kai Ora (National Māori Organics Authority of Aotearoa) J. Hutchings et al, 'Hua Parakore: An indigenous food sovereignty initiative and hallmark of excellence for food and product production' (2012) 1(2) MAI Journal 131.

18 Interview with spokesperson for Vanuatu Tourism Ambassador programme, 15 August 2014.

19 C.F. Koya VAKa'Uta, 'Anthropological evidence of the 15 intended iTaukei Tapa cloth designs', Google docs, 2013, online: <https://docs.google.com/file/d/0B0fYC2m4wjFqcHl Bc2xSQjVmMG8/edit?usp=sharing\&pli=1> accessed 05/11/2013. See also R. CHAndAR, 'Women's Group Opposes Trademarking of Fijian Motifs' Fijilive, 3 February 2013 <pidp.og> accessed 20/03/2015.

20 The government of Fiji has a majority (51\%) ownership stake, B. EGAN, 'Appropriation (?) of the Month: Fiji Masi for Air Pacific or for Everyone?', Intellectual Property Issues in Cultural Heritage (IPinCH) <www.sfu.ca/ipinch/outputs/blog/appropriation-month-fiji-masi-airpacific-or-everyone $>$ accessed 19/04/2015.

21 Air PAcific, 'Fiji's national airline achieves another milestone in turnaround strategy: new name, new aircraft, increased frequency, and improved product', Media release, 14 May 2012 <www.fijiairways.com/about-fiji-airways/2012-media-centre/fiji-airways/> accessed 19/04/2015. See also E. Baselala, 'Air Pacific to be rebranded "Fiji Airways"' Fiji Times, 15 May 2012. 
carrier.'22 Masi, generically widely known as tapa, also called ngatu in Tonga and siapo in Samoa, is cloth made from mulberry tree bark which is often decorated, either through free-hand painting, stencilling, smoking or dyeing. In pre-contact Fiji, masi was used for religious ritual use, daily household use (for example for clothing and mattresses) and for socio-cultural ceremonial use. ${ }^{23}$ The making of masi was, and continues to be, largely the prerogative of women. Today masi has a deep cultural significance for many Fijians and plays an important part in cultural exchanges that reinforce relationships between individuals, families and other groups. Some of the motifs or designs used on the cloth are associated with particular areas and are said to be able to be identified by anyone with a trained eye. Although distinctive to certain parts of Fiji, masi designs also share a common heritage with ngatu and siapo designs in Tonga and Samoa. ${ }^{24}$ Vaka'uta argues that the historical evidence shows that the motifs are similar to those used in Lapita pottery and traditional tattoo designs, and that the designs are 'markedly similar' in all three of these countries as a result of the ongoing patterns of cultural exchange. ${ }^{25}$

In deliberately incorporating masi designs into its new image, Fiji Airways was consciously capitalising on the cultural resonance of these designs for Fijians, as well as their aesthetic appeal to foreigners. Indeed, it appears to have been a very successful strategy at least financially: Fiji Airways managed to go from close to bankruptcy four years ago to posting a record profit in July 2014. ${ }^{26}$

Fiji Airways proceeded by contracting a local Fijian masi maker, Makareta Matemosi, to produce a series of fifteen designs for them. Tragically, Matemosi died in early 2015. Although there is a persistent misunderstanding in Fiji that Makareta Matemosi was chosen because she won a competition, it appears she was chosen because had contributed to a book on Fijian masi which the airline had come across and been attracted to one of her designs on the front cover. ${ }^{27}$ The airline arranged for an Australian designer to work with Matemosi, guiding her with images about the sorts of visual messages the airline was hoping to convey, and she came up with fifteen different motifs, all with associated meanings that

22 Air PACIFIC, 'Air Pacific reveals new brandmark for "Fiji Airways"', Media release, 17 August 2012 <www.fijiairways.com/about-fiji-airways/2012-media-centre/new-brandmark/> accessed $19 / 04 / 2015$.

23 VAKA'Uta above n. 19.

24 See P.-A. Addo, Creating a Nation with Cloth: Women, Wealth and Tradition in the Tongan Diaspora, Berghahn Books, Oxford 2013.

25 VAkA'Uta above n. 19. See also W. Cowling, 'The Lapita Motif that "Got Away"' (2009) 6(2) Sites: New Series 57 <sites.otago.ac.nz> and more widely R. Neich and M. Prendegast, Pacific Tapa, University of Hawai'i Press, Honolulu 2004.

26 FijI AIRWAYs <www.fijiairways.com/about-fiji-airways/media-centre/fiji-airways-reportsrecord-\$172m-operating-profit-for-first-half-year/> accessed 21/04/2015. Operating profit of $\$ 17.2 \mathrm{~m}$ from 1 January to 30 June 2014.

27 C. SpICER and R.B.B. Me, Fiji Masi: An Ancient Art in the New Millennium, Star Printery, Suva 2004. 
she provided. ${ }^{28}$ All the motifs are relatively simple and share a considerable number of features with many in the 'database' of traditional motifs. ${ }^{29}$ The fifteen new motifs have been incorporated by the airline everywhere in their livery, from the chairs, to the blankets, to the menus, including the plane tail of the new Airbus A330 itself. This re-branding scheme was extensively advertised and Matemosi herself was heaped with public acclaim. The new motifs were warmly greeted by Fijians as a fitting tribute to their cultural heritage and generated large amounts of cultural pride, especially with the arrival of the newly painted Airbus. However, this public support turned to public disapprobation when Fiji Airways made an application to register the fifteen motifs as trademarks under the Trademarks Act (Fiji) in January 2013.

The trademark application gave rise to furious public debate, in which outrage was expressed that anyone, particularly a corporate entity, could attempt to claim ownership over such Fijian cultural heritage. ${ }^{30}$ A Methodist pastor was so incensed by this move that he had one of the motifs tattooed onto his arm. The debate was particularly heated in the social media, and a Facebook page was created, 'NA NODA MASI - Do Not TM our cultural heritage', ${ }^{31}$ and a petition to the Prime Minister was launched that garnered almost 2,000 signatures. ${ }^{32}$ A central underlying concern was that the trademark claim would give the airline exclusive ownership and use of the motifs and prevent masi makers and others from using them without the airline's permission. ${ }^{33}$ For example, a newspaper article reported a community leader stating: 'We are worried as once this is officially patented we cannot use most of these designs, and it is the sacred identity of the vanua of Cakaudrove.' ${ }^{4}$ There were also concerns that such an application undermined Fijian cultural identity, showed a lack of respect for Fijian culture, and was an attempt to claim something that does not belong to

28 Rod Ewins, an international expert on masi, has observed that meanings associated with designs do not operate at the prosaic level of 'this represents or stands for that' but rather at a far more subtle symbolic level. As such, the type of over-simplification done by the airline detracts from true understanding of Fijian art and how it operates. Personal communication from Rod Ewins, 15 November 2014.

29 VAKA'UtA above n. 19.

30 See for example the reaction of Fiji Women's Rights Movement in Fiji Times, 'this latest action clearly shows how Fiji Airways wants to possess and control culture', E. BASELALA, 'Air Pacific to be rebranded "Fiji Airways"' Fiji Times, 15 May 2012.

31 NA NODI MASI - Do Not TM our cultural heritage <www.facebook.com/fijimasiforevery one> accessed 19/04/2015.

32 Pax Viti, 'Petition to Prime Minister Voreqe Bainimarama: Appeal to stop Air Pacific trademarking 15 distinct masi motifs', change.org, $2013<$ www.change.org/p/primeminister-voreqe-bainimarama-appeal-to-stop-air-pacific-trademarking-15-distinct-masi-mo tifs?utm_campaign=friend_inviter_modal\&utm_medium $=$ facebook\&utm_source $=$ share_ petition\&utm_term=permissions_dialog_false $>$ accessed 20/04/2015.

33 Pax Viti above n. 32.

34 L. Rawalai, 'Masi Design Concerns', The Sunday Times (Fiji), 10 February 2013, p. 3 $<$ www.facebook.com/fijimasiforeveryone/photos/a.652745184751806.157522.6478306252432 $62 / 659520247407633 /$ ?type $=1 \&$ theater $>$ accessed 19/04/2015. 
the airline. ${ }^{35}$ One community spokesperson stated: 'these are designs that are ours alone, something that has been part of our identity and we have never been approached or consulted by the company that now lays claim over it. ${ }^{36}$ It was also pointed out that the designs being claimed were similar to those that form part of Samoan and Tongan cultural heritage, and should not be claimed by a Fijian national company. The public debate consistently maintained a clear line in expressing appreciation for Fiji Airways' promotion of Fijian cultural heritage through its re-branding, but opposition to the trademark application. Throughout this barrage of negative publicity the airline has remained silent. ${ }^{37}$

During field work conducted in July 2014, masi makers and other artists continued to raise concerns about Fiji Airways 'claims' over the masi, in particular that they may somehow be stopped from making masi or using the designs. These concerns were compounded by a lack of understanding about intellectual property laws, prompting fears about what conduct such laws may enable, regardless of their actual effect. Such problems of perception about intellectual property law are particularly marked in the region owing to the lack of professional guidance and explanation, its own history of strong customary intellectual property rights, its experiences with resource misappropriation by foreigners, and bio-piracy narratives that circulate in social media.

In terms of legal opposition, however, the only actual opponents were two academics from the University of the South Pacific who did not have any formal legal advice, just the assistance of a foreign legal academic. Unlike the Vanuatu and the Samoan legislation discussed below, the Fijian Act does not have any specific provisions dealing with traditional knowledge. The opponents therefore had to argue from first principles. They argued, essentially: that Fiji Airways could not claim to be the 'proprietor' of the trademarks as required by section 11 of the Act, as the marks claimed are traditional designs owned by the Fijian people; that the marks are not 'distinctive' as required by section 8(2) of the Act as they are well-known throughout the Pacific as being Fijian designs owned by Fijian people; and that the marks are 'disentitled to protection in a court of justice' and 'contrary to law or morality' as provided in section 10 of the Act. They also argued that it would be contrary to Fiji's international commitments under the Convention for the Safeguarding of the Intangible Cultural Heritage, which it ratified on 19 January 2010, on the grounds that allowing a corporate entity to have a monopoly of use over fifteen designs would be directly contrary to Fiji's obligations to safeguard this important cultural practice under Article 11(a) of the Convention. These arguments were supported by a detailed anthropological report setting out historical evidence of designs that closely resemble thirteen of the fifteen trademark applications (the other two were acknowledged to be

RaWALAI above n. 34 .

RAWALAI above n. 34 .

EgAN above n. 20. 
original creations). ${ }^{38}$ Affidavits from the Ministry of iTaukei (Indigenous Fijian) Affairs outlined concerns about the trademark application ('Our argument is that it is traditional knowledge and should not be trademarked') but the Ministry does not appear to have made a formal opposition.

The airline lodged a counter-statement to the notice of opposition. The essence of their argument was that: the fifteen motifs are original designs, although based on Fijian cultural heritage; and that Fiji Airways commissioned and now owns the intellectual property in these and that they are therefore eligible for registration. They also claim that the airline had no intention of preventing masi makers from using traditional designs, and notes that the Solicitor-General has the power to impose disclaimers, conditions and limitations that may resolve such concerns.

Although the trademark application was lodged in January 2013 and the counter-statement to the notice of opposition was lodged in September 2013, as at April 2015, the Trademark Registry has not made a decision in the matter - consistent with the long history of allowing trademark oppositions to pend indefinitely. As a result, many Fijians are of the opinion that Fiji Airways gave up on its trademark claim in response to the negative publicity it received, and it has even been reported in a New Zealand newspaper that the opponents won the case. ${ }^{39}$

This incident has been framed as another example of cultural misappropriation by a corporate entity, ${ }^{40}$ but it is in fact far more multi-dimensional, and in many ways sheds light on vexed issues of cultural change, the tensions between economic and cultural imperatives, and changing notions of creativity. ${ }^{41}$ It also helps to illustrate some of the difficulties that arise in using legal frameworks to deal with these issues, whether these are global models or local variants such as sui generis traditional knowledge legislation. In order to develop these points further, we now turn to discuss some insights garnered from interviews with masi makers and sellers at the Suva flea market, and with Makareta Matemosi, the artist at the centre of the controversy.

It is clear that the masi industry in Fiji is currently in a state of flux (and probably has been for a while). ${ }^{42}$ There are ongoing changes in the technology

38 VAKA'UTA above n. 19.

39 M. FIELD, 'Designer sorry after cultural dressing down', STUFF Co.NZ <www.stuff.co.nz/lifestyle/fashion/9222652/Designer-sorry-after-cultural-dressing-down> accessed 19/04/2015.

40 See Egan above n. 20.

41 In Vanuatu designs based on traditional sand drawing have been used on postage stamps with far less controversy, perhaps because of the recognition that while on one level these are seen as symbols of Vanuatu identity they are also recognised as being multi-functional and serving a variety of purposes including commercial ones see UNESCO, 'Vanuatu Sand Drawings' <www.unesco.org/culture/ich/en/RL/00073> accessed 19/04/2015. See also K. Huffman, 'Su tuh netan "monbwei”: we write on the ground' in J. Bonnemaison, K. Huffman and D. Tryon (eds.), Arts of Vanuatu, Crawford House Publishing, Bathhurst 1996, p. 250.

42 See R. EwIns, Staying Fijian: Vatulele Island Barckcloth and Social Identity, Crawford House Publishing, Bathurst 2009, in particular Chapter 3. 
and in the networks surrounding masi making, which have a profound impact upon the ways in which designs, patterns and motifs are being used and accessed. For instance, whereas traditionally stencils for the particular motifs were made with leaves, today they are made from hard plastic. These stencils, which embody designs used from many different islands, are being sold to buyers who value them for their aesthetic appeal and who want a variety of motifs to choose from in creating their decorative masi ('masi kesa'). Another major change is the introduction of specialisation in the different steps in masi making. Previously masi makers were responsible both for making the white masi and also for decorating it, but increasingly today the white masi is being produced on one island and then sold to buyers who apply their own designs to make their masi kesa. The production of masi requires the cultivation of mulberry trees and these are no longer widely available in Fiji; but on one island, Vatulele, mulberry trees today are planted as plantations and the sale of masi is an important income stream for the community. The knowledge about the production of masi (mulberry tree cultivation, harvesting, production) ${ }^{43}$ is therefore becoming geographically restricted, and is also incorporating innovations such as the use of corrugated iron sheeting for 'speed' drying. This move away from the traditional closed community network of masi kesa production to a more open and geographically mixed network is symptomatic of the increased intermixing of communities within Fiji, as a result of urbanisation. It is also strongly associated with the increasing influence of the cash economy and the reality that masi kesa is now bought and sold in the marketplace, often by wholesalers. Although there is an important market in masi kesa for tourists, the majority of the masi kesa produced is for the local market, ${ }^{44}$ some of which goes abroad via the Fijian diaspora.

The designs on the masi kesa are also currently in a state of flux. There continues to be a strong tradition amongst some communities, particularly on the island of Moce, to make masi kesa in accordance with traditional patterns and arrangements of motifs that signify their group identity. ${ }^{45}$ Amongst such communities and masi makers, the customary protocols that govern these designs and who can use them are still extremely important. One masi maker explained that she had obtained the knowledge and the rights to use the Moce masi designs through her husband's line, and that she did not use patterns from other places as she was not entitled to do so. She was disapproving of the women who used designs from other places, but noted that there was nothing she could

\footnotetext{
43 Ewins describes the chemical processes that masi making entail: R. EwINs, 'Dard Hunter and the Bark-Paper of the Pacific, Insights into Technical, Technological and Cultural Affinities', Friends of Dard Hunter Inc., Oregon 2000 <www.justpacific.com/art/articles/paper/ hunter\%26bark-paper.pdf> accessed 21/04/2015.

44 Ewins above n. 43 estimates that only $20 \%$ is sold for tourists, p. 46.

45 See Ewins above n. 43, p. 158.
} 
do about it. Ewins similarly observes that " [b]orrowing" and "standardisation" are often contested by the original "copyright owners." 46

However, there is also a growing body of masi makers, seller and buyers who are increasingly conceptualising masi kesa production primarily as an aesthetic endeavour, and they select the designs to use (conveniently on hand through the stencils) based on the most visually pleasing arrangement of particular motifs. One masi maker commented: 'I have a number of customers who give me orders and I try really hard for them to make really beautiful pieces so I use the different designs that catch my eye. This is when my artistic side comes out. I need to have different patterns I can use.' Another stated: 'There are lots of new designs coming up, now you don't know which is from where. Before everyone knew which designs came from which particular place. This is all changing now, it is all being mixed up.' However, although these interviewees expressed narratives that contrasted the traditional (static) use of designs with the present dynamic processes, anthropologist Koya suggests that in fact there has always been a continual process of change:

'An important part of the process of Tapa production (Masi, Kupesi [Ngatu] and Siapo) continues to be the rearrangement of these designs into new motifs as shown in a number of identified designs. Through the cultural circulation of Tapa, these designs become formalized and other women begin to use them in their creations. In this way, new derivates become common use motifs. ${ }^{47}$

Her observations are supported by the detailed commentary on Fijian masi by Rod Ewins in his monograph on the subject. ${ }^{48}$

This mixing up of designs from different geographical locations is complemented by a breakdown in the exclusive nature of some types of decoration reserved in the past for chiefs and nobles; for example traditionally such pieces were smoked to produce a brownish colour all over in certain areas, but today these smoking techniques are used widely and there are no restrictions on who can purchase such pieces. Finally, there have also been significant innovations in the clothing designs associated with masi kesa, particularly in regard to wedding dresses. It is now common for 'western' style wedding dresses to be made entirely from masi and masi kesa, as well as creative combinations of traditional and western clothing. This presents an interesting reverse scenario to the use by a New York fashion designer discussed below.

As might be expected, there is a wide variety of opinions about these changes in practice. Some people are disapproving, and are concerned that that such

Ewins above n. 43, p. 157.

Koya above n. 19, p. 13.

EwINs above n. 43, particularly Chapter 5 . 
mixing up will undermine cultural identities and traditions. For example, a spokesman from the Ministry of iTaukei Affairs stated:

'if people start to use Traditional Knowledge from other places then this starts to weaken the link that people from a particular place have with their Traditional Knowledge. This is important because it is people's identity, this is what connects a person and their particular area. It creates a cultural sense of identity, to know that you are from a particular place and have these specific types of designs and other Traditional Knowledge. We need to keep this link intact. ${ }^{49}$

His comments resonate with those made by those of the Secretary of the National Council of Chiefs in Vanuatu, in relation to similar processes at play in Vanuatu. He stated that he wants laws introduced to stop people making things that are the kastom of other places, such as weaving patterns, carving designs and so forth. He envisages that registration may be a way to establish who can claim the rights over what, but acknowledges that there are likely to be disputes over entitlements. He also saw control over women as being central to maintaining control over traditional knowledge, suggesting that women who marry into different communities 'mas lego ol fasin blong hem mo mekem fasin blong long $w e$ ' (should 'leave' their traditional knowledge behind in their home village and adopt the traditional knowledge of their husband's community). ${ }^{50} \mathrm{He}$ also considered that it would be the appropriate role of the chiefs to tell women what they could and could not weave. This demonstrates once again that traditional knowledge and control over it is affected by, and affects, a broad range of social and cultural issues, that there are many different viewpoints, power dynamics and agendas involved, and hence that its regulation cannot be considered in a way that is divorced from such context.

On the other hand, another common opinion is that the new focus on aesthetic qualities is simply an inevitable consequence of the demands of the cash economy; one masi maker stated: 'I am just doing it to make money, the stencil designer is just making money, the person putting the designs on the tapa is just making money.' For such women, they are simply responding to the changing desires of customers, who are increasingly attracted by aesthetic qualities in the masi kesa, as opposed to its embodiment of particular traditional designs and values. They are aware of a degree of disapproval regarding their practices, but justify themselves both by reference to the need to make money and by the fact that what they are producing is art. The Fiji Airways case was in many ways a catalyst for the expression of these various viewpoints, highlighting practices that have obviously been occurring for some time.

49 Interview with spokesman at Ministry of iTaukei Affairs, 15 July 2014.

50 Interview with Secretary of the Malvatumauri, Port Vila, 16 August 2014. 
This leads our discussion straight to the figure at the centre of the Fiji Airways controversy, Makareta Matemosi, a masi maker originally from Namuka island in the Lau group, and who was a resident of the Namuka community in a settlement just outside of Suva. In recent years, Matemosi's fortunes were closely tied with the Fiji Airways re-branding and trademark claim. Initially she was publicly fêted for her beautiful work, and was used extensively by Fiji Airways in their publicity campaign around the new brand. This apparently gave rise to some jealousy and complaints, especially from some communities in the Lau island group who thought that it was not fair that all the praise was centred on her as an individual when the designs she had created were based heavily on their traditional designs. ${ }^{51}$ However, such jealousy remained largely unarticulated until Fiji Airways made the trademark claim, which precipitated an avalanche of criticism and personal attacks on Matemosi. One woman stated that she had:

'suffered as a result of this claim, lots of people have said bad things about her. They have been cursing her. They say, "how come she is claiming it?" She is from a different island in the Lau group. When I saw what was being said in the newspaper and on the television I felt for her. It is just because it concerned a lot of money, that is all. I hope that she got paid a lot. People went for her, they criticized her, they did not see that it was a big company behind her. ${ }^{32}$

Matemosi herself confirmed the terrible impact the Fiji Airways trademark claim had had on her reputation and on her business. She said that people came to see her in her home and told her that they were not happy with her because now Fiji Airways could stop them from using masi. She continued:

'At first I was really happy, but then when the trademark issue came I really regretted that I had done it. That is the best word to use the express it, regret. I did not know that people would complain. It has really badly affected me and my family. My children told me that they read about people complaining about me on Facebook, and there were all sorts of stories going around ... All this has really spoiled my business, it has not recovered since then. People thought that I got paid a lot of money but I did not, and now my business is really small. This is a problem because my husband does not work, I am the only one who earned money with my masi making business. Now I cannot pay the kids' school fees. ${ }^{53}$

Matemosi said that she had subsequently been told by many people that she should have asked permission to use the designs that she based her designs on. While she remained of the opinion that she was free to draw on them owing to her family heritage, and that she had created new designs, she did acknowledge that involving

Interview with iTaukei Affairs, above n. 49.

Interview with masi seller, Suva, Fiji, 12 July 2014.

Interview with Makareta Matemosi, 25 July 2014. 
either customary bodies or the Ministry of iTaukei Affairs could have avoided the situation she found herself in. A salient factor here is that Matemosi did not live on her home island, but in a settlement in town where customary protocols are far less visible. She considered herself an artist whose work for Fiji Airways was an opportunity to show Fijian masi to the world. She also saw it as an opportunity to forge a new artistic direction in masi making, stating: 'I did not do it just for the money. I did it because I wanted to create a change for the Fijian ladies. I do not think we should continue just to copy this and copy that. I wanted to show the Fijian ladies that we can create our own designs. ${ }^{54}$ Matemosi also was dismissive of suggestions of dualism between traditional and economic imperatives, seeing them as being able to be mutually reinforcing. She had cultivated a deep understanding of the traditional meanings of masi designs and used these insights to create her new designs. She believed that when people use masi kesa for customary purposes then the traditional motifs should be used and people should use their own motifs and understand the meaning of them. But for commercial purposes, she believed they should be able to mix it all around and use the designs that they want.

This case study offers us a number of relevant insights. The first is that although this dispute appeared to be over intellectual property claims, in fact it is actually part of a far more complex set of issues that centre on processes of social, cultural and economic change and exchange. This reinforces the arguments made throughout this book that intellectual property rights cannot be analysed in a cultural vacuum, but need to be considered within particular social contexts. It also makes it apparent that the law and legal frameworks in this area cannot offer complete solutions, and in many ways are relatively marginal to the (gradual) resolution of the issues, although they do have the potential to establish important framing principles. ${ }^{55}$

The social and cultural impacts of intellectual property claims need to be taken into account by policy makers and by corporate bodies such as Fiji Airways, whose claims can precipitate the types of impact on individuals illustrated by the case of Matemosi. The problematic nature of such tensions may be avoided, at least in part, by working through relevant customary and state bodies and being responsive to the relational dimensions involved in the transaction. Rather than just focusing its publicity on the creative genius of an individual, Fiji Airways could have also publicly recognised the contributions of the communal cultural heritage from which the designs were inspired, and perhaps made a financial contribution to an initiative associated with the promotion of masi techniques. Given the newness of the concept of trademarks, particularly in the context of cultural heritage, Fiji Airways may have been able

\footnotetext{
$54 \quad$ Interview with Makareta Matemosi, 25 July 2014.

55 See similarly regarding traditional legislation: G. Pigliasco, 'The Innovation of Tradition' Anthropology News, American Anthropology Association, n.d. <http://dev.aaanet.org/index. $\mathrm{php} / 2014 / 03 / 13 /$ the-innovation-of-tradition/> accessed 21/04/2015.
} 
to alleviate public concerns by press releases outlining their reasons for the trademark application, and clearly stating their intention not to prevent any nonairline related use of masi. In Chapter 8 we discuss another case study which also involves the commercialisation of traditional knowledge, in this case a traditional cough remedy, but which has been done in such a way as to avoid, to date, the types of problematic concerns generated by Fiji Airways' claims.

A second linked insight is that most people who discussed this issue, like Matemosi, do not see a necessarily diametric opposition between commercialisation and cultural respect and integrity per se. Rather, they see a need for processes of commercialisation to accommodate customary obligations. ${ }^{56}$ Such accommodations are commonly thought to involve acknowledgment of the origins of the derivation of the designs; the need to ask for permission before use; and the need for some type of sharing of the commercial benefits with the design source community. However, working out how exactly to ensure that each of these can occur is extremely complex, particularly given the realities of population movements and breakdown in traditional authority structures. The historical fluidity in the sharing and exchange of different motifs and their gradual geographic spread over time renders identifying particular ownership groups problematic. The response of the Fijian government to these issues is a multi-pronged strategy that integrates traditional knowledge legislation, revival programmes and initiatives, and an ambitious cultural mapping project that involves compiling a database of all the traditional knowledge in Fiji. ${ }^{57}$ As none of these components are finalised, and the public information about them is restricted, it is too early to assess their success in facilitating the meeting of the desires of acknowledgment, authorisation and sharing. What is clear is that any legal or non-legal mechanism that is put in place will need to take into account and alleviate the following risks:

- the risk of preventing the cross-fertilisation of ideas and concepts that is essential for creativity and innovation (the 'chilling' power of the law). This risk includes both the actual restrictions imposed by any new laws and also any perceived restrictions, as these can also exert a powerful restraining influence as we saw in the case-study about people's fears concerning their rights to continue to make masi following Fiji Airways trademark claim;

56 A working example can be found in the context of Maori tattoo where the term Ta moko is used to differentiate authentic or traditional maori tattoo designs from adaptations of these which are referred to as kirituhi. On the challenges of tradition and change See S. Pritchard, 'Essence, Identity, Signature: Tattoos and Cultural Property' (2000) 10(3) Social Semiotics 331, who also draws attention to the 'newly traditional'.

57 A description of this initiative is provided by the Ministry of iTaukei Affairs (Fiji) 'Itaukei intellectual property rights and cultural mapping project' <www.fijianaffairs.gov.f/IILC\%20 IPR.html>. The SPC has also published a Pacific Intangible Cultural Heritage Mapping Toolkit: K. Teaiwa and C. Mercer, Pacific Cultural Mapping Planning and Policy Toolkit, Secretariat of the Pacific Community, Noumea 2011 <www.acpcultures.eu/_upload/ocr_ document/SPC_PacificCultMapPlanPolToolkit_2011.pdf> accessed 13/04/2015. 
- the risk that benefit sharing and prior informed consent arrangements can be dominated by certain powerful individuals and/or agencies to gain control in similar ways to what has occurred with tangible resources such as land, timber and mineral wealth as discussed in Chapter 4, and dispossess those lacking in power or voice, such as women;

- the risk that the mechanisms devised are practically unusable due either to lack of administrative capacity to operationalise them, or the costs of bringing enforcement actions; and

- the risk that certain forms of 'branding' whether by trademarks, marks of authenticity or origin, will force indigenous cultural expression into certain manifestations and projections of what is 'traditional' in order to meet particular market demands. This could result in innovators and 'new' traditionalists choosing to operate outside this framework in order to enjoy greater freedom of cultural expression

Such mechanisms should also pay due regard to the question of where such disputes/negotiations as do arise should be resolved. Legal forums such as courts have an extremely limited remit in dealing with broad cultural issues, and the more flexible mechanisms of customary institutions, where they exist, or some form of hybrid institution ${ }^{58}$ may be better adapted to working out mutually satisfactory solutions. ${ }^{59}$ In the context of the Fiji Airways case study there were suggestions about the need for customary processes of apology, explanation, public discussion and possibly some form of compensation made by some of the key figures involved. ${ }^{60}$ However, such institutions may also problematically disempower women as is suggested in the comments by the Secretary of the Malvatumauri set out above. An alternative approach of regulatory convening such as recently proposed by Drahos is also of great potential in this context. ${ }^{61}$

A third insight is that the intersection of trademarks and cultural heritage/ traditional knowledge is likely to be an ongoing source of tension unless clear mechanisms are put in place to deal with the issue of applications to register such trademarks. It is inevitable that there will be ongoing attempts by companies to capitalise on the goodwill associated with particular cultural references. Such applications give rise to two separate types of concerns. One involves trademarks that are offensive or bring the cultural heritage into disrepute, for example the

58 See for example D. Evans, M. Goddard and D. Paterson, 'The Hybrid Courts of Melanesia: Comparative Analysis of Village Courts of Papua New Guinea, Island Courts of Vanuatu and Local Courts of Solomon Islands', Justice and Development Working Paper Series 62097 13/2011, Justice for the Poor, World Bank 2011.

59 See Chapter 4 and the new dispute forums suggested under the Customary Land Management Act in Vanuatu.

60 Ministry of iTaukei, Matemosi, Community leader, T. Vuibau, 'Cultural Identity' Fiji Times Online, 16 February 2013 <www.fijitimes.com/story.aspx?id=225369> accessed 19/04/2015.

61 P. Drahos, Intellectual Property, Indigenous People and their Knowledge, Cambridge University Press, Cambridge 2014, Chapter 5. 
use of the Fijian word for Fiji, 'viti', currently being used to brand toilet paper, which some have claimed is offensive for indigenous Fijians. ${ }^{62}$ The other involves the types of issues raised by the Fiji Airways case, where the claim is seen to enable a business or individual to gain some type of monopoly rights over a particular aspect of cultural heritage that many different groups also have claims over. These issues have been extensively explored in the literature in the context of countries where non-indigenous companies use signs of indigenous people. ${ }^{63}$ Such practices are starting to be curtailed as a result of a combination of changes in laws, discussed below, and as business ethics start to take into account the problematic nature of such trademarks for indigenous people. However, these issues are even more complex in the context of a region such as Pacific islands where there may be a large number of local (indigenous) businesses that may wish to use a particular expression of indigenous culture.

A number of different responses to these issues have been explored in jurisdictions around the world, but most accommodations in the legislation do not address the full extent of the concerns raised. One approach is to create quite specific lists or categories of cultural heritage that cannot be registered, such as chiefly titles or place names. For instance, the approach taken in the United States is to disallow the registration of marks that falsely suggest a connection with particular Native American tribes. This is supported by the establishment of a database in which all tribes may deposit their official insignia which can then be used by the Trademark Office in making decisions about whether the mark can be registered. ${ }^{64} \mathrm{~A}$ similar type of registration system has been established under the Cook Islands Traditional Knowledge Act 2013 as discussed in Chapter 8, although it is not explicitly linked to trademark. Fiji has also taken a small step in this direction by enacting a decree that limits the circumstances in which a trademark that includes the word 'Fiji' can be registered. ${ }^{65}$ This follows the worldwide success of 'Fiji Water', which is in fact one hundred per cent owned by a non-Fijian privately held company. ${ }^{66}$ Samoa has gone one step further and excludes from registerability marks based on matai (chiefly) titles, names of persons or Samoan villages, or religious words or symbols. ${ }^{67}$

62 This may also be illegal under the Trade Marks (Amendment) (No 2) Decree 2012.

63 See for example 'Intellectual property and Traditional Cultural Expressions' in S. Von Lewinski (ed.), Indigenous Heritage and Intellectual Property, Wolters Kluwer 2008, Part III, section II, Chapter 3. United States Patents and Trademarks Office, Native American Tribal Insignia <http://patents.uspto.gov/trademarks/law/tribal/index.jsp> accessed 19/04/2015. b05/Decree-No-65_2012---Trade-Marks-\%28Amendment\%29\%28No-2\%29-.aspx> accessed 21/04/2014. Also available via PacLII.org.

66 See M. Kaplan, 'Fijian Water in Fiji and New York: Local Politics and a Global Community' (2007) 22(4) Cultural Anthropology 685.

67 Section 47 Intellectual Property Act 2011 (Samoa). 
Another approach is to focus on the prevention of registering marks that would be offensive to a particular cultural group. New Zealand's Trademark Act 2002 contains a provision that a trademark application can be denied on the grounds of cultural offence to significant sections of the community, and in particular Maori (section 17(1)(c)(i)). ${ }^{68}$ A committee composed of people knowledgeable about the worldview, protocol and culture of the Maori provides advice to the Commissioner on the issue of whether the mark is likely to offend. A Maori tribal spokesman commented on this system fairly negatively, observing:

\begin{abstract}
'what you end up with is this pan-tribal mish-mash of capacity and skills that make high level decisions which, whilst convenient for the government to have their one stop shop, actually undermines the diverse governance structures of the individual tribal entities. So you end up with a monocultural view of what is and what is not offensive. So they actually end up undermining our culture ... [Another] thing we have found is that if, for example, we have to say what is special [so] then [they] can categorise what is not special. Also the problem is that then if we say that certain things are offensive then it is assumed that everything else is not offensive.' 69
\end{abstract}

The most extensive restrictions on registration of trademarks containing indigenous knowledge found in the region (and possibly globally) are in the Vanuatu legislation. Part 15 of the Vanuatu Trade Mark Act 2002 prohibits the registration of trademarks that involve an expression of indigenous culture unless the prior informed consent of the custom owners has been obtained or, failing that, an agreement has been entered into with the National Council of Chiefs. This mechanism requires the Registrar to be able to identify that a particular application does involve an expression of indigenous culture as a first step, which may be more difficult if the Act is administered through a regional office as discussed above. It also means that procedures must be established to determine who the custom owners are, and how prior informed consent can be achieved, all fraught issues that have been discussed at length elsewhere, and which would not, even if hypothetically relevant in the case of Fijian masi, have helped resolve the issues. To date these provisions has not been used, although a Memorandum of Understanding was signed between the Vanuatu Intellectual Property Office and the National Council of Chiefs in late 2014 to develop a mechanism to implement such provisions.

68 See S. Frankel, 'Third Party Trade-Marks as a Violation of Indigenous Cultural Property: A New Statutory Safeguard' (2005) Journal of World Intellectual Property $83<\mathrm{http}: / / \mathrm{ssrn} . c 0 \mathrm{~m} /$ abstract $=1862685>$ and O. Morgan, 'Protecting Indigenous Signs and Trade Marks under the New Zealand Trade Marks Act 2002'. See also Ministry of Commerce (NZ), Maori Trade Marks Focus Group, Maori and trade marks: a discussion paper, Ministry of Commerce, Wellington 1997 <http://catalogue.nla.gov.au/Record/1550570> accessed 19/04/2015. 


\section{GLOBAL CERTIFICATION SCHEMES}

Fairtrade and similar types of certification marks, such as the Forest Stewardships Council, have been identified as offering particular benefits for local and indigenous businesses in the developing world. ${ }^{70}$ There has been considerable interest in, and experimentation with, these schemes in the region. Fairtrade (FLO Cert) certification appears to be working in certain niche areas, such as coffee production in Papua New Guinea, ${ }^{71}$ but has not had a broad uptake and is not applicable in regard to any handicraft production. ${ }^{72}$ The most active type of certification in this area is organic certification standards and marks, which have been developed through a regional network that is now spearheaded by the Pacific Organic and Ethical Trade Community (POETCom) that is housed in the Secretariat of the Pacific Community (SPC). Organic farming in the region has been identified as an important niche market to develop which also builds upon strong de facto organic farming traditions. ${ }^{73}$

POETCom developed the Pacific Organic Standard (POS) in 2008 in recognition of the fact that the region needed its own standard to reflect the particular nature of its agricultural systems. This includes the context of smallholder tenure systems, tropical agriculture, atoll agriculture, and the variety of crops that are grown, some of which are not common outside the region, such as for example noni. The POS was developed with input by organic producers, research organisations and national governments with the objective of being both appropriate and relevant for the region. It is the only standard in the world that includes culture and traditions, and these were incorporated to recognise the fact that organic farming in the region is indelibly linked with culture and traditional farming practices that are increasingly under threat. ${ }^{74}$ This flexibility in designing a unique standard is facilitated within the global organic system through its international harmonisation and equivalence process, which has developed ways of measuring technical equivalence of standards worldwide.

70 See for example C. Graber and J. LAI, 'Indigenous cultural heritage and Fairtrade: voluntary certification standards in the light of WIPO and WTO law and policymaking' (2011) 29(3) Prometheus: Critical Studies in Innovation 287.

71 OXFAM, Learning from Experience: Sustainable Economic Development in the Pacific, Oxfam, New Zealand 2010, p. 22 </resources/onlinereports/learning-from-experience-final. pdf $>$ accessed 19/04/2015.

72 In its 2010 investigation into FLO certification in the Pacific Oxfam (above n. 71, pp. 22-23) identified two main problems: first, the costs of certification are high relative to the scale of production in most Pacific countries; and second, certification requires the formation of democratic producer's organisations which does not reflect the organisational structure of most farming groups in the region that are essentially extended family and clan systems. Cf however Maori Organic which is based on family farms.

73 See above regarding the take up of this in New Zealand by Maori communities.

74 Secretariat of the Pacific Community, Pacific Organic Standard 2008 <http://asia.ifad. org/web/poetcom/resources/-/resource_library/6882/normal?_1_WAR_resource_libraryport let_redirect=http $\% 3 \mathrm{~A} \% 2 \mathrm{~F} \% 2>$ accessed $21 / 04 / 2015$. 
Through this process, the POS has been assessed as technically equivalent to the European Union's organic standard, and the Australian Organic Standard. One of the key elements that assists such harmonisation is that organic certification is, at its heart, a system based on broad principles about the importance of clean, safe, environmentally friendly food which all the different organisations involved adhere to.

A major hurdle for farmers wishing to use the POS or alternative organic certifications in the region has been the high cost of third party certification owing to the need to pay inspectors from Australia or New Zealand. In order to overcome this problem, POETCom is developing a Participatory Guarantee System (PGS). The essence of such a system is that it allows particular groups to develop their own systems for ensuring compliance with the standard and auditing is based on peer review to ensure that those systems are followed. There are a number of advantages to a PGS as opposed to third-party certification in the region: it encourages and supports training and capacity building in understanding the organic standard, its importance and its application; it considerably reduces compliance costs; it encourages peer-to-peer learning as farmers learn techniques from those they audit; and it encourages local ownership of the organic standard. A final advantage is that the PGS can be adapted to build upon and support the particular community structures that underlie the different farming groups that wish to develop their own PGSs. For example, POETCom is currently trialling the PGS in three different communities: the Sabeto Organic Papaya Association (SOPA) which is a group of farmers based in a peri-urban area of Fiji who grow papaya; farmers on Cicia, an island in Fiji, who produce virgin coconut oil; and the entire island of Abaiang in Kiribati. In Cicia the PGS was developed on the basis of the traditional authority of the chiefs who took a collective decision through their island council not to allow fertilisers onto the island. This use of the existing customary system that people trust and follow gave important strength and credibility to the PGS. In Abaiang in Kiribati the island council was also central to the development of the PGS and assisted in developing it through the creation of an Organic By-law.

The PGS system works through the operation of an inter-linked series of reviews and audits, the exact nature of which increasingly varies the further down the process one goes. For example, in Cicia each farm is required to be reviewed through a peer review process that requires participation of $70 \%$ of all the farmers that are actively farming in the village. The process of review is determined by the farmers themselves based on the most appropriate ways of ensuring that the different aspects of the organic standard are being applied. In this way it allows a great degree of flexibility that can take into account the particular circumstances of production, for example the planting of yam which has particular cultural practices in different communities. This farm-level peer review process is organised at a village level, and this in turn is overseen by the 
island-level Cicia Organic Monitoring Agency (COMA) which has the power to award PGS organic certification. COMA is in turn regularly audited and reviewed by POETCom's Standards and Certification Committee, although eventually it is planned that there will be a national authority to take over this function.

The Pacific Organic Standard and the Participatory Guarantee Scheme, once fully established, will be complemented by the use of the Organic Pasifika trademark which is owned by SPC on behalf of POETCom. Through the promotion of a regional trademark, many different levels of producers will be able to benefit from far broader levels of marketing than they would if they were responsible for developing and promoting their own branding. ${ }^{75}$ This in turn will strengthen the capacity of the region to niche market Organic Pasifika produce abroad.

As discussed further below, this regional approach to certification and branding, which guarantees quality while encouraging diversity and local relevance, is a model that could also be of use in a broader context than organic certification. Such an approach may be a fruitful way to proceed in developing branding schemes that can be used in the context of production of a whole range of cultural industries, such as handicraft production and tourist operations.

\section{LABELS OF AUTHENTICITY}

There is considerable literature discussing the complex issues involved in developing labels of authenticity for indigenous minorities in developed countries. ${ }^{76}$ One of the biggest problems has been how to define authenticity, when indigenous groups are often composed of many different sub-groups and individuals who have integrated with the dominant culture to varying degrees. One possible solution to this problem could be the development of a system along the lines of the PGS that permits smaller groupings than the 'national' to determine for themselves the appropriate standards and limits. A PGS also involves peer review, thus reducing the costs and difficulties associated with auditing and enforcement of authenticity marks.

Labels of authenticity are just starting to be explored in the region, as they are seen as presenting a possible solution to a common problem of cheap imported 'knock off' products that are produced in Asia and sold to tourists as local handicrafts. The need for this was demonstrated in a survey conducted in Vanuatu in 2014 that found that ninety per cent of handicrafts sold at the

75 Much of the information in this section was based on an interview conducted with representatives of POETCom in Suva, Fiji, 16 July 2014.

76 See for example D. Zografos, Intellectual Property and Traditional Cultural Expressions, Edward Elgar, Cheltenham 2010, Chapter 4; P. ChAlk and A. Dunlop, 'Indigenous Trade Marks and Human Rights: An Australian and New Zealand Perspective' (2009) 99 Trademark Reporter 956. 
local handicraft market were imported. ${ }^{77}$ In Vanuatu alone there have been three different initiatives launched to try to promote local handicrafts in recent times: the Vanuatu Tourism Ambassador Programme's association with the 'mamma's market'; the establishment of the Port Vila Community Handicraft Centre, which guarantees that it only sells only genuine Vanuatu local products and value added goods; and a new initiative launched by an NGO: ACTIV. ${ }^{78}$ This latter initiative is a geographically regulated scheme whereby all the goods sold at their market house are stated to be made entirely of natural materials by ni-Vanuatu. ${ }^{79}$ The focus is not so much on 'authentic' goods in terms of using traditional forms or designs, but more on the sale of goods produced using resources readily at hand as a way of providing a source of income for people in rural communities. The problem of a lack of certification scheme is to an extent mitigated by the fact that it is reasonably obvious that the goods have been made 'in place' as they contain only natural products that are handmade.

Another type of branding initiative currently being explored is 'Made in' country schemes. To date, Fiji has led the way in this direction, developing a series of eight different industry emblems: Fijian Made, Fijian Assembled, Fijian Packed, Fijian Designed, Fijian Crafted, Fijian Sewn, Fijian Grown and Fijian Product. Each emblem represents a different set of compliance criteria that designates what products qualify to be registered to use the emblem. For example, to be registered as Fijian Crafted requires that 'the handicraft use as its major components locally sourced materials that are weaved, crafted, and stringed to depict authentic Fijian craft.' 80 Such criteria should eliminate confusion with products that are produced in Asia. However, it falls short of addressing other concerns about the commodification of handicraft production, such as the loss of cultural value and integrity that comes from the mass production of handicrafts as opposed to their production by hand, and the dividing line between local sourced materials and those that are not, may be difficult to draw (for example, plastic beads, clasps for necklaces, inks, paints, etc.). Moreover the proliferation of categories may run into the same type of problems experienced in New Zealand (discussed above) where it was found that this type of branding did not lead to market growth whereas the reputation of particular artists - many of whom chose to operate outside the mark system - did have positive effects.

The scheme was established in 2011, initially just for Fijian Grown and Fijian Made, with the dual objectives of developing and promoting locally grown produce or products made in Fiji and branding and promoting locally produced

\footnotetext{
77 Interview with spokesperson for Vanuatu Tourism Ambassador programme, 15 August 2014.

78 P. GiL, 'Reviving Local Handicrafts' (2014) 14 Island Life 6.

79 The ACTIV Centre - ACTIV Association <www.activassociation.org/the-activ-centre.html> accessed 19/04/2015.

80 Compliance Criteria for the Use of the Emblem <www.fijianmade.gov.f//images/complience. pdf $>$ accessed 19/04/2015.
} 
or manufactured products. ${ }^{81}$ It is based on a registration process administered by the Ministry of Industry and Trade that requires applicants to make a statutory declaration that their products meet the relevant compliance criteria. Failure to use the emblem in accordance with these conditions is punishable by a substantial fine or imprisonment. ${ }^{82}$ More than 800 products (in all the categories) have been registered since the scheme started, and the Attorney General has claimed that there has been a 'spike in commercial interest in local artisans' since the Fijian Crafted programme was launched. The President of the Fiji Crafts Council also stated that the initiative had led to a surge in sales for those artisans with licences. ${ }^{83}$ The scheme was extended in 2014 by a new initiative involving an agreement made by the Ministry with several of the big duty free shops to designate part of their floor space solely to 'Fijian Crafted' products. The scheme is designed to work by creating public awareness leading to consumer pressure on retailers to support locally made handicraft producers and to offer their products for sale. To date, the policing and enforcement of this system has been relatively informal, with no regular inspections. Officers in the Ministry stated that they were presently relying primarily on reporting of incorrect usage of the emblems by the registered users, but that no such complaints have as yet been lodged. The potential of such a scheme to support local handicraft producers is significant, and it demonstrates the value of strong state involvement in this area. However, it will also require greater investment in terms of compliance procedures in order to ensure that the guarantee of authenticity that is claimed can truly be relied upon by consumers. A 2011 inquiry into Geographical Indicators (GIs) and trademarks for products based on bio-cultural heritage globally found that 'GIs and certification trademarks for traditional goods are useless without good standards of quality control and marketing. ${ }^{\text {' }} 4$ These comments are equally applicable to Fijian Made and similar schemes. Moreover while these schemes may be useful in domestic markets, there is little to stop entrepreneurs outside the region capitalising on associations with the Pacific for marketing purposes.

Industry Emblem Decree 2011, section 3.

Industry Emblem Decree 2011, section 4.

Fijian Government Media Centre, 'More Local Artisans Receive "Fijian Crafted" Licences', 30 November 2013 <www.fiji.gov.fj/Media-Center/Press-Releases/MORELOCAL-ARTISANS-RECEIVE--FIJIAN-CRAFTED\%E2\%80\%9D-LICEN.aspx> accessed $19 / 04 / 2015$.

84 G. Dutfield, Intellectual Property Tools for Products Based on Biocultural Heritage, International Institute for Environment and Development (IED), London 2011, p. 25. 


\section{GIs AND COLLECTIVE MARKS}

Geographical Indications of Origin (GIs) and collective trademarks have also been identified as possible mechanisms that will allow communities in the region to collectively protect various aspects of their cultural heritage and traditions. Indeed, GIs have been extensively promoted in the region by the European Union, largely on the basis that they have been effective in Europe in allowing small-scale producers of agricultural products and speciality food to more successfully market and protect their products, ${ }^{85}$ although this has sometimes entailed extensive litigation. ${ }^{86}$ GIs essentially allow producers that have developed a particular product that is associated with their geographical area (for example, champagne from Champagne) to stop others from associating their products with the GI. Whilst some developing countries, in particular India, have responded enthusiastically to the potential of GIs, many scholars have raised serious doubts about their potential for producers in less and least developed countries, especially for products that have not already achieved significant commercial success. ${ }^{87}$ It is argued that the economic case for GI protection is weak, that establishing domestic GI regimes entails significant cost, and that in order to work they are dependent upon a whole range of extraneous factors, such as the establishment of a strong consumer base that is willing to pay a price premium on particular products. ${ }^{88}$ This in turn also requires significant investment in terms of marketing and consumer education. Currently very few domestic GI systems exist in the region, with the most developed being Samoa's Intellectual Property Act 2011. ${ }^{89}$

85 See M. Blakeney, 'The Pacific Solution: The European Union's Intellectual Property Rights Activism in Australia's and New Zealand's Sphere of Influence' in P. Drahos and S. Frankel, Indigenous People's Innovation, ANU ePress 2012, pp. 178-187.

86 Parma ham and champagne are examples of successes.

87 Dutfield, above n. 84; S. Frankel, 'The Mismatch of Geographical Indications and Innovative Traditional Knowledge' (2011) 29(3) Prometheus 253. See also M. Handere and R. Burrell, 'GI Blues: The Global Disagreement over Geographical Indications' in K. Bowrey, M. Handler and D. Nicol (eds.), Emerging Challenges in Intellectual Property, Oxford University Press, Oxford pp. 126-144.

88 A 2009 study found that GIs may be of benefit to developing countries that are able to provide: strong organisational and institutional structures to maintain, market, and monitor the geographical indication; equitable participation among producers and enterprises in a region; the existence of strong market partners; and effective legal protection at the domestic level. D. Giovannucci, T. Josling, W. Kerr, B. O'Connor and M.T. Yeung, Guide to Geographical Indications: Linking Products and their Origins, International Trade Centre, Geneva 2009 $<$ www.intracen.org/WorkArea/DownloadAsset.aspx?id=37595> accessed 19/04/2015.

89 There is limited reference to these in the preamble of the Papua New Guinea Patents and Industrial Designs Act 2000, which provides that the Act is 'an Act to make provision for the protection industrial property rights, namely patents, industrial designs and geographical indications and for related purposes', but there is no further reference to 'geographical indications' in this legislation. In Tonga there is a Protections of Geographical Indications Act 2002 which provides for the registration of geographical indications. These are defined as 'an indication which identifies a good as originating in the territory of a country, or a region 
In terms of assessing the suitability of GIs for countries in the region it is instructive to look at the regulatory mechanisms currently in place over one of the products that has been identified as being most able to profit from GI protection, Vanuatu kava. ${ }^{90}$ In the face of continued expressions of concerns about the unregulated nature of the industry, a Kava Act was introduced in 2002, but there has been a continual failure to administer the legislation, leading to the continuation of a system where the variety of kava being sold is still not being effectively regulated. There is also ongoing disagreement about the operation of the trade between Vanuatu and the other major island producers. ${ }^{91}$ Such administrative realities need to be taken into account before embracing GIs. As a masters study into the potential usefulness of a GI for Samoan noni juice found, '[i]t takes time to establish product quality and reputation, with the possibility that the GI may use scarce resources - over a long period of time - which may already be stretched in developing countries like Samoa and become insufficient to apply usefully.' 92

An alternative to a GI that also permits collective protection of certain types of intellectual property, and may be more flexible and responsive to existing local conditions, is collective trademarks. Collective marks are currently used informally in the region by community groups that do not have any legal status. For example, some of the women who are involved in the Roi Mata World Heritage project produce handicrafts that are all affixed with a label that reads 'Chief Roi Mata's Domain, Vanuatu'. Rather than opting for trademark protection, the group relies upon strong customary norms to assist them in making sure that no other group makes use of the mark.

There are quite flexible provisions allowing for the registration of collective marks in many countries in the region that may be used by such communitybased groups if stronger (i.e. state-based) protection becomes necessary. For example, the Industrial Property Act 1994 of Tonga provides in section 31 that an applicant for a collective mark simply needs to designate the mark as a collective one and to accompany the application with a copy of the conditions governing the use of the mark. These types of provisions give a great deal of

or locality in that territory, where a given quality, reputation or other characteristic of the good is essentially attributable to its geographical origin'.

D. Downes and S. LAIRD, Innovative Mechanisms for Sharing Benefits of Biodiversity and Related Knowledge: Case Studies on Geographical Indications and Trademarks, prepared for UNCTAD Biotrade Initiative, 1999 <www.ciel.org/Publications/InnovativeMechanisms.pdf> accessed 19/04/2015.

91 N. Pollock, 'Sustainability of the Kava Trade' (2009) 21(2) The Contemporary Pacific 265, $283-284$.

92 It should be noted that this thesis actually concluded that a GI could be of advantage to the nonu industry in Samoa, but that it would require extensive support as it details. See M. Plant, 'Place-making in the Pacific: Can Geographical Indications Support the Sustainable Development of the Nonu Industry in Samoa?', Master of Development Studies Thesis, Victoria University of Wellington, April $2013<$ http://researcharchive.vuw.ac.nz/ $\mathrm{xmlui} /$ bitstream/handle/10063/3085/thesis.pdf?sequence $=2>$ accessed 27/04/2015. 
leeway to a group in developing their own standards and conditions that may apply to the use of the mark, and they avoid groups being required to adopt some form of legal structure before registering a mark. Although to date there has been almost negligible interest shown in the use of collective marks in the region, this is clearly an area that could be developed more in the future, particularly in the context of the development of cultural industries. Unlike GIs, collective trademarks can be used by groups organised around factors other than place, such as for example communities of artists. Such flexibility may help to avoid potential difficulties in making decisions about various types of boundaries and membership of groups. It may also open up alternatives for communities that have historical but not actual geographic ties to place, such as migrant communities within the Pacific islands themselves. On the downside, allowing Pacific islanders outside the region to use such marks may dilute the benefits of use for in-country initiatives. However, the agency that such schemes give small groups in being able to determine their own standards needs to be weighed against the advantages that can come from a national or even regional authenticity mark that can be supported by extensive branding and product development, as indicated above and discussed in the conclusion. Another difficulty may be in determining which individual should be the owner of the collective trademark, ${ }^{93}$ and whether that 'ownership' could give rise to the types of problems we have referred to in Chapter 4.

\section{CUSTOMARY PROTOCOLS, EDUCATION AND NEGATIVE PUBLICITY}

The final tool to be considered to address and prevent cases of misappropriation of traditional expressions of culture by those outside the region is the use of negative publicity campaigns or public shaming. Ideally this can be coupled with awareness-raising about customary understandings about what 'belongs' to the people of the region, so as to prevent such incidents in the first place.

There have been two recent examples that illustrate the effectiveness of these mechanisms. The first was the launch by Nike in 2013 of a range of 'Pro Tattoo Tech Gear' that included sports bras, leggings, jumpsuits and singlets and was said to have been inspired by traditional tatau (tattoo) of the Pacific. This led to an uproar from the Samoan community both in Samoa and in diaspora communities abroad, particularly in New Zealand, as the women's leggings gave an appearance that the wearer had a $p e^{\prime} a-$ a traditional tattoo reserved for men. It was also claimed that the range involved an exploitation of the art of Samoan

93 The experiences those in the Potato Park in Peru have had with collective trademarks is insightful: see A. Argumedo, Collective Trademarks and Biocultural Heritage, IIED 2013 <http://pubs.iied.org/pdfs/16528IIED.pdf> accessed 19/04/2015. 
people. ${ }^{94}$ In light of the public criticisms of the new range, Nike quickly decided to pull the line and issued an apology, stating: 'We apologise to anyone who views this design as insensitive to any specific culture. No offence was intended.'95

A second example was the launch of a new range of dresses by well-known New York fashion designer Nanette Lepore. She called her range the 'Aztec' range but the design used bore a striking similarity to traditional Fijian masi designs. This also prompted letters of protest and finally led to a campaign using social media. An open letter was posted on the designer's Facebook page accusing her of taking 'designs and patterns from the islands of Fiji and the Fijian people' and not acknowledging them. ${ }^{96}$ An online petition was also launched calling for her to ' $[\mathrm{s}]$ top appropriating traditional Fijian tapa designs and motifs and calling it "Aztec" or "African" or any other culture not its own for that matter. ${ }^{\text {'97 }}$ Lepore initially defended her designs but then finally issued an apology, stating 'I am truly sorry for misnaming the Aztec Dress' and 'I respect local artists everywhere and I apologise for any offence this has caused. ${ }^{98}$ A key figure in the campaign against Lepore was a New York-based Tongan artist, Vaimoana Niumeitolu, who was the one who posted the letter on the Facebook page. She provided some important insights into this incident, demonstrating the importance of not viewing it as a simple case of wilful disregard of cultural heritage, drawing on her twin perspectives of herself as a New Yorker and a Pacific islander. Two weeks after the letter was written, she was contacted by Lepore's office and a meeting was set up for them to discuss the incident. Niumeitolu's intention for the meeting was to educate Lepore about the value that Fijian and Tongan cultures put on masi, and she said that the meeting was a great success, leading to the apology and the removal of the dresses from the rack and for sale online. She explained: 'I don't think they really took on board the message before then because in New York, it's like a bubble, it is its own world. The South Pacific is nothing, letters from New Zealand and other places just seemed so far away.' She considers that she was ultimately able to get through because she is also an artist and lives in New York City, demonstrating the value of networks in diaspora communities and the importance of personal, as well as electronic, advocacy.

94 G. Coutrs, “No Offense Meant” as Nike withdraws Samoan tattoo range' Radio Australia, 15 August 2013 <www.radioaustralia.net.au/international/radio/program/pacific-beat/ no-offense-meant-as-nike-withdraws-samoan-tattoo-range/1176266> accessed 19/04/2015.

V. Tapaleao, 'Nike commits cultural faux pas' NZ Herald, 14 August $2013<$ www.nzherald. co.nz/business/news/article.cfm?c_id=3\&objectid=10912088 $>$ accessed 19/04/2015. M. FIELD, 'Designer sorry after cultural dressing down', STUFF Co.NZ < www.stuff.co.nz/lifestyle/fashion/9222652/Designer-sorry-after-cultural-dressing-down> accessed 19/04/2015.

97 'Stop appropriating traditional Fijian tapa designs and motifs and calling it "Aztec" or "African" or any other culture not its own for that matter', online petition change.org $<$ www.change.org/p/nanette-lepore-stop-appropriating-traditional-fijian-tapa-designs-andmotifs-and-calling-it-aztec-or-african-or-any-other-culture-not-its-own-for-that-matter> accessed 19/04/2015.

98 MaiLIFE, 'The "Aztec" dress design that is causing a row', 7 August $2013<$ www.mailife.com. fj/the-azec-dress-design-that-is-causing-controversy/> accessed 19/04/2015. 
The meeting also led to an ongoing collaboration designed to bring the South Pacific islander community in New York and the fashion industry into closer discussion, and which will hopefully lead to the development of a code of ethics or guiding protocols. Niumeitolu argues that 'at the moment the educational angle is what is missing from the conversation. People are accused of being racist or bad people [when they misappropriate] but this is not necessarily the case, often it is just that they do not have the education necessary to inform them of the issues.' She said that Lepore had not been aware that the design had a masi origin, and had chosen it on aesthetic grounds from several that were presented to her by a designer in her company. Niumeitolu believes that the solution to many of these vexed issues of appropriate use of cultural heritage lies in continual dialogue and opportunities to hear people express different viewpoints. As a member of a diaspora community herself, who draws from both Tongan cultural traditions and the streets of the South Bronx, she sees the importance of not excluding those living outside their countries of origin from having the ability to also draw on such a heritage, as well as the importance of doing so in a respectful way. She concluded: 'I live in a completely different world to someone raised in Tonga. If these factors [that I am a woman and living abroad] automatically cut me off, then I cannot deal with those factors, that doesn't create anything. ${ }^{99}$

\section{CONCLUSION: PROPOSAL FOR A REGIONAL CULTURAL HERITAGE BRANDING SCHEME}

To conclude, we draw together the insights from the themes explored in this chapter to propose a new cultural heritage branding scheme which could operate at a number of levels from local to regional. This scheme is based on the value of promoting local products that are embedded within their local/cultural and social context and whose production reinforces important cultural practices or values. It draws upon the increasingly well-recognised value of bio-cultural heritage, which has been defined as 'not just knowledge, innovations, practices and technologies, but the biological, cultural and spiritual context from which these emerge and are continually renewed.' ${ }^{\prime} 00$ This bio-cultural heritage is both of value to the Pacific island countries themselves, ${ }^{101}$ and also potentially of value to an external market seeking 'authentic' indigenous products and experiences. A local gallery owner in Samoa recently argued that education

\footnotetext{
99 Telephone interview with Vaimoana Niumeitolu, 15 April 2014.

100 DutFiELD above n. 84, p. 9.

101 See M. Forsyth, 'Alternative Development Paradigms in Vanuatu and Beyond' (2014) 25 SSGM In Brief <http://ips.cap.anu.edu.au/sites/default/files/SSGM\%20IB\%202014_25\%20 Forsyth\%20Proof\%202.pdf> accessed 21/04/2014.
} 
about the processes behind handicraft production is a key way to improve their value, stating:

'It is apparent that the major issues regarding the sale and prices of handcrafts in Samoa are driven by lack of ready markets and fair representation on behalf of the artists. With regard to siapo making in particular it also amounts to ignorance by the buyer of the complexity of the process of making siapo. Once the buyer was [sic] informed of the time, effort and skill required to be a siapo artist, they will be willing to pay a more realistic prices for the siapo.'102

The idea of a cultural heritage branding scheme proposed here is inspired by a number of different concepts. An important one is the One Village One Product (OVOP) project that originated in Japan as a movement based on the idea that each village should come up with a product which is unique in the world, but could be promoted under a national OVOP scheme. This was extremely successful and has been replicated in a number of other countries at national level. ${ }^{103}$ Such a scheme is based on the idea of a national scheme that values and responds to local differences, in a similar way to the theory underlying the PGS and even the Pacific organic standard itself. The scheme is also inspired by GIs as discussed above, and authenticity marks in New Zealand, such as the Maori Toi Iho mark which finally seems to be taking off after a number of false starts. ${ }^{104}$

The premise of the scheme is that each group that wants to participate should nominate and develop a particular product or service (such as a tourism venture) that the group sees as culturally valuable and as having economic potential. It can be traditional or modern (or more likely a blend of each), but its manufacture or production should in some fundamental way support the region's cultural heritage (for example, facilitating transfer of knowledge to the next generation, reviving endangered aspects of culture, supporting key cultural values). The

102 Dr V. Taule'Alo, 'Are We Exploiting our Siapo Makers and Samoan Artists?' Samoa Observer, 6 January 2014 <www.samoaobserver.ws/observer-stuff/arts-observer/9269-arewe-exploiting-our-siapo-makers-and-samoan-artisans> accessed 21/04/2015.

103 See Zogafros above n. 76, pp. 132-136. See also The One-Village-One-Product (OVOP) movement: What it is, how it has been replicated, and recommendations for a UNIDO OVOPtype project <www.unido.org/fileadmin/user_media/Publications/Research_and_statistics/ Branch_publications/Research_and_Policy/Files/Working_Papers/2008/WP032008\%20The \%20One-Village-One-Product\%20\%28OVOP\%29\%20movement.pdf> accessed 19/04/2015.

104 According to Johnsson, "[w]hile, overall, the introduction of the toi ihoTM mark has been beneficial to artists and consumers alike, the certification mark was disinvested in 2010 . Some of the reasons for the disinvestment were that: (a) toi ihoTM no longer fitted in the strategic priorities of Creative New Zealand; (b) there was insufficient funding and resources to run the scheme appropriately; (c) the breadth of the scheme's design was too wide. Despite the disinvestment, artists have not been deregistered and the toi ihoTM scheme is currently in a transition phase.' D. Johnsson, 'The Branding of Traditional Cultural Expressions: To Whose Benefit?' in Drahos and Frankel above n. 85, p. 147. The Toi Iho is now administered as a Charitable Trust by a wholly Maori body. See <www.toiiho.co.nz/about-toi-iho/> accessed $21 / 04 / 2015$. 
group would also have to develop its own set of internal regulations, setting out the types of products covered, the membership of the group, representation of the group, how any benefits received are to be distributed or costs shared and the ways in which the group's activities support cultural heritage. Yearly selfreporting or peer review, following the PGS model, against the community's own criteria to maintain registration may be an effective way of monitoring the operation.

In terms of global markets, the most effective administration of this scheme would ideally be at a regional level where an agreed registration process could be used to authorise the use of the cultural heritage mark to groups that satisfactorily met the accepted criteria. In the absence of regional IP laws, in-country trademark law and possibly unfair competition and or passing off laws, as well as the threat of negative publicity campaigns, could be utilised to protect the mark from misuse. It is clear from the discussion in this chapter that in order to be successful any branding scheme needs to be scaffolded with supporting institutions which empower communities and local businesses to understand and benefit from the system. It is also clear that the success of any such scheme in commercial terms needs to be accompanied by extensive advertising and market development. ${ }^{105}$ There is therefore, due to the size of the many industries in the region, a compelling case for considering pooling resources at a regional level through focusing on developing a single mark standing for cultural authenticity for an international market. It is also clear that any scheme needs to be flexible enough to be adapted to the various different realities amongst producer groups for there to be real local ownership and longterm use.

This proposal shares many similarities with a proposed scheme to establish bio-cultural heritage indications in Peru. The latter is a 'legal regime that protects and promotes bio-cultural expressions and is sensitive to the local customary laws and practices that sustain bio-cultural heritage.'106 Such indications would focus on protecting and promoting not only final products but also distinct socio-cultural production processes, including networks of cultural, socio-economic and ecological relationships and values, people and interconnections. ${ }^{107}$ As with that scheme, the regional scheme proposed here is still very much in a preliminary conceptual form. The idea is merely to illustrate the possibilities of branding schemes to positively reinforce cultural values, and the need to think creatively about developing schemes that support relevant local priorities, rather than merely adopting models from elsewhere that have been developed in different contexts.

\footnotetext{
105 See OXFAM above n. 71.

106 Argumedo above n. 93.

107 Argumedo above n. 93, p. 26.
} 